\title{
Strong convergence theorem for quasi-Bregman strictly pseudocontractive mappings and equilibrium problems in Banach spaces
}

\author{
Godwin C Ugwunnadi ${ }^{1,2}$, Bashir Ali ${ }^{3^{*}}$, Ibrahim Idris ${ }^{3}$ and Maaruf S Minjibir ${ }^{3}$
}

"Correspondence:

bashiralik@yahoo.com

${ }^{3}$ Department of Mathematical

Sciences, Bayero University Kano,

P.M.B. 3011, Kano, Nigeria

Full list of author information is

available at the end of the article

\begin{abstract}
In this paper, we introduce a new iterative scheme by a hybrid method and prove a strong convergence theorem of a common element in the set of fixed points of a finite family of closed quasi-Bregman strictly pseudocontractive mappings and common solutions to a system of equilibrium problems in reflexive Banach space. Our results extend important recent results announced by many authors.

MSC: 47H09; 47J25
\end{abstract}

Keywords: Bregman distance; quasi-Bregman strictly pseudocontractive map; fixed point

\section{Introduction}

Let $E$ be a real Banach space and $C$ a nonempty closed convex subset of $E$. The normalized duality map from $E$ to $2^{E^{*}}$ ( $E^{*}$ is the dual space of $E$ ) denoted by $J$ is defined by

$$
J(x)=\left\{f \in E^{*}:\langle x, f\rangle=\|x\|^{2}=\|f\|^{2}\right\} .
$$

Let $T: C \rightarrow C$ be a map, a point $x \in C$ is called a fixed point of $T$ if $T x=x$, and the set of all fixed points of $T$ is denoted by $F(T)$. The mapping $T$ is called $L$-Lipschitzian or simply Lipschitz if there exists $L>0$, such that $\|T x-T y\| \leq L\|x-y\|, \forall x, y \in C$ and if $L=1$, then the map $T$ is called nonexpansive.

Let $g: C \times C \rightarrow \mathbb{R}$ be a bifunction. The equilibrium problem with respect to $g$ is to find $z \in C$ such that $g(z, y) \geq 0, \quad \forall y \in C$.

The set of solution of equilibrium problem is denoted by $\operatorname{EP}(g)$. Thus

$$
\operatorname{EP}(g):=\{z \in C: g(z, y) \geq 0, \forall y \in C\} .
$$

Numerous problems in physics, optimization and economics reduce to finding a solution of equilibrium problem. Some methods have been proposed to solve the equilibrium

○2014 Ugwunnadi et al.; licensee Springer. This is an Open Access article distributed under the terms of the Creative Commons Attribution License (http://creativecommons.org/licenses/by/2.0), which permits unrestricted use, distribution, and reproduction in any medium, provided the original work is properly cited. 
problem in Hilbert spaces; see for example Blum and Oettli [1], Combettes and Hirstoaga [2]. Recently, Tada and Takahashi [3, 4] and Takahashi and Takahashi [5] obtain weak and strong convergence theorems for finding a common element of the set of solutions of an equilibrium problem and set of fixed points of a nonexpansive mapping in Hilbert space. In particular, Takahashi and Zembayashi [4] established a strong convergence theorem for finding a common element of the two sets by using the hybrid method introduced in Nakajo and Takahashi [6]. They also proved such a strong convergence theorem in a uniformly convex and uniformly smooth Banach space.

Reich and Sabach [7] and Kassay et al. [8] proved some convergence theorems for the solution of some equilibrium and variational inequality problems in the setting of reflexive Banach spaces.

Let $\phi: E \times E \rightarrow[0, \infty)$ denote the Lyapunov functional defined by

$$
\phi(x, y)=\|x\|^{2}-2\langle x, J y\rangle+\|y\|^{2}, \quad \forall x, y \in E .
$$

A mapping $T: C \rightarrow C$ is said to be quasi- $\phi$ strictly pseudocontractive, see [9], if $F(T) \neq \emptyset$ and there exists a constant $k \in(0,1]$ such that

$$
\phi(p, T x) \leq \phi(p, x)+k \phi(x, T x), \quad \forall x \in C \text { and } p \in F(T) .
$$

Let $E$ be a real reflexive Banach space with norm $\|\cdot\|$ and $E^{*}$ the dual space of $E$. Throughout this paper, we shall assume $f: E \rightarrow(-\infty,+\infty]$ is a proper, lower semi-continuous and convex function. We denote by $\operatorname{dom} f:=\{x \in E: f(x)<+\infty\}$ the domain of $f$.

Let $x \in \operatorname{int} \operatorname{dom} f$; the subdifferential of $f$ at $x$ is the convex set defined by

$$
\partial f(x)=\left\{x^{*} \in E^{*}: f(x)+\left\langle x^{*}, y-x\right\rangle \leq f(y), \forall y \in E\right\}
$$

where the Fenchel conjugate of $f$ is the function $f^{*}: E^{*} \rightarrow(-\infty,+\infty]$ defined by

$$
f^{*}\left(x^{*}\right)=\sup \left\{\left\langle x^{*}, x\right\rangle-f(x): x \in E\right\} .
$$

We know that the Young-Fenchel inequality holds:

$$
\left\langle x^{*}, x\right\rangle \leq f(x)+f^{*}\left(x^{*}\right), \quad \forall x \in E, x^{*} \in E^{*}
$$

A function $f$ on $E$ is coercive [10] if the sublevel set of $f$ is bounded; equivalently,

$$
\lim _{\|x\| \rightarrow+\infty} f(x)=+\infty
$$

A function $f$ on $E$ is said be strongly coercive [11] if

$$
\lim _{\|x\| \rightarrow+\infty} \frac{f(x)}{\|x\|}=+\infty
$$

For any $x \in \operatorname{int} \operatorname{dom} f$ and $y \in E$, the right-hand derivative of $f$ at $x$ in the direction $y$ is defined by

$$
f^{\circ}(x, y):=\lim _{t \rightarrow 0^{+}} \frac{f(x+t y)-f(x)}{t} .
$$


The function $f$ is said to be Gâteaux differentiable at $x$ if $\lim _{t \rightarrow 0^{+}} \frac{f(x+t y)-f(x)}{t}$ exists for any $y$. In this case, $f^{\circ}(x, y)$ coincides with $\nabla f(x)$, the value of the gradient $\nabla f$ of $f$ at $x$. The function $f$ is said to be Gâteaux differentiable if it is Gâteaux differentiable for any $x \in \operatorname{int} \operatorname{dom} f$. The function $f$ is said to be Fréchet differentiable at $x$ if this limit is attained uniformly in $\|y\|=1$. Finally, $f$ is said to be uniformly Fréchet differentiable on a subset $C$ of $E$ if the limit is attained uniformly for $x \in C$ and $\|y\|=1$. It is well known that if $f$ is Gâteaux differentiable (resp. Fréchet differentiable) on int $\operatorname{dom} f$, then $f$ is continuous and its Gâteaux derivative $\nabla f$ is norm-to-weak* continuous (resp. continuous) on int $\operatorname{dom} f$ (see also [12, 13]). We will need the following results.

Lemma 1.1 [14] Iff $: E \rightarrow \mathbb{R}$ is uniformly Fréchet differentiable and bounded on bounded subsets of $E$, then $\nabla f$ is uniformly continuous on bounded subsets of $E$ from the strong topology of $E$ to the strong topology of $E^{*}$.

Definition 1.2 [15] The function $f$ is said to be:

(i) essentially smooth, if $\partial f$ is both locally bounded and single-valued on its domain;

(ii) essentially strictly convex, if $(\partial f)^{-1}$ is locally bounded on its domain and $f$ is strictly convex on every convex subset of dom $\partial f$;

(iii) Legendre, if it is both essentially smooth and essentially strictly convex.

Remark 1.3 Let $E$ be a reflexive Banach space. Then we have:

(i) $f$ is essentially smooth if and only if $f^{*}$ is essentially strictly convex (see [15],

Theorem 5.4);

(ii) $(\partial f)^{-1}=\partial f^{*}($ see $[13])$;

(iii) $f$ is Legendre if and only if $f^{*}$ is Legendre (see [15], Corollary 5.5);

(iv) if $f$ is Legendre, then $\nabla f$ is a bijection satisfying $\nabla f=\left(\nabla f^{*}\right)^{-1}$, $\operatorname{ran} \nabla f=\operatorname{dom} \nabla f^{*}=\operatorname{int} \operatorname{dom} f^{*}$ and $\operatorname{ran} \nabla f^{*}=\operatorname{dom} f=\operatorname{int} \operatorname{dom} f$ (see [15],

Theorem 5.10).

Examples of Legendre functions were given in $[15,16]$. One important and interesting Legendre function is $\frac{1}{p}\|\cdot\|^{p}(1<p<\infty)$ when $E$ is a smooth and strictly convex Banach space. In this case the gradient $\nabla f$ of $f$ is coincident with the generalized duality mapping of $E$, i.e., $\nabla f=J_{p}(1<p<\infty)$. In particular, $\nabla f=I$ the identity mapping in Hilbert spaces. In the rest of this paper, we always assume that $f: E \rightarrow(-\infty,+\infty]$ is Legendre.

Let $f: E \rightarrow(-\infty,+\infty]$ be a convex and Gâteaux differentiable function. The function $D_{f}: \operatorname{dom} f \times \operatorname{int} \operatorname{dom} f \rightarrow[0,+\infty)$, defined as follows:

$$
D_{f}(y, x):=f(y)-f(x)-\langle\nabla f(x), y-x\rangle
$$

is called the Bregman distance with respect to $f$ (see [17]). It is obvious from the definition of $D_{f}$ that

$$
D_{f}(z, x)=D_{f}(z, y)+D_{f}(y, x)+\langle\nabla f(y)-\nabla f(x), z-y\rangle .
$$

Recall that the Bregman projection [18] of $x \in \operatorname{int} \operatorname{dom} f$ onto the nonempty, closed, and convex set $C \subset \operatorname{dom} f$ is the necessarily unique vector $P_{C}^{f}(x) \in C$ satisfying

$$
D_{f}\left(P_{C}^{f}(x), x\right)=\inf \left\{D_{f}(y, x): y \in C\right\} .
$$

Concerning the Bregman projection, the following are well known. 
Lemma 1.4 [19] Let $C$ be a nonempty, closed, and convex subset of a reflexive Banach space $E$. Let $f: E \rightarrow \mathbb{R}$ be a Gâteaux differentiable and totally convex function and let $x \in E$. Then:

(a) $z=P_{C}^{f}(x)$ if and only if $\langle\nabla f(x)-\nabla f(z), y-z\rangle \leq 0, \forall y \in C$;

(b) $D_{f}\left(y, P_{C}^{f}(x)\right)+D_{f}\left(P_{C}^{f}(x), x\right) \leq D_{f}(y, x), \forall x \in E, y \in C$.

Let $f: E \rightarrow(-\infty,+\infty]$ be a convex and Gâteaux differentiable function. The modulus of the total convexity of $f$ at $x \in \operatorname{int} \operatorname{dom} f$ is the function $v_{f}(x, \cdot):[0,+\infty) \rightarrow[0,+\infty]$ defined by

$$
v_{f}(x, t):=\inf \left\{D_{f}(y, x): y \in \operatorname{dom} f,\|y-x\|=t\right\} .
$$

The function $f$ is called totally convex at $x$ if $v_{f}(x, t)>0$ whenever $t>0$. The function $f$ is called totally convex if it is totally convex at any point $x \in \operatorname{int} \operatorname{dom} f$ and is said to be totally convex on bounded sets if $v_{f}(B, t)>0$ for any nonempty bounded subset $B$ of $E$ and $t>0$, where the modulus of the total convexity of the function $f$ on the set $B$ is the function $v_{f}: \operatorname{int} \operatorname{dom} f \times[0,+\infty) \rightarrow[0,+\infty]$ defined by

$$
v_{f}(B, t):=\inf \left\{v_{f}(x, t): x \in B \cap \operatorname{dom} f\right\} .
$$

Lemma 1.5 [20] If $x \in \operatorname{dom} f$, then the following statements are equivalent:

(i) the function $f$ is totally convex at $x$;

(ii) for any sequence $\left\{y_{n}\right\} \subset \operatorname{dom} f$,

$$
\lim _{n \rightarrow+\infty} D_{f}\left(y_{n}, x\right)=0 \Rightarrow \lim _{n \rightarrow+\infty}\left\|y_{n}-x\right\|=0 .
$$

Recall that the function $f$ called sequentially consistent [19] if for any two sequences $\left\{x_{n}\right\}$ and $\left\{y_{n}\right\}$ in $E$ such that the first one is bounded

$$
\lim _{n \rightarrow+\infty} D_{f}\left(y_{n}, x_{n}\right)=0 \Rightarrow \lim _{n \rightarrow+\infty}\left\|y_{n}-x_{n}\right\|=0 .
$$

Lemma 1.6 [21] The function $f$ is totally convex on bounded sets if and only if the function $f$ is sequentially consistent.

Lemma 1.7 [22] Let $f: E \rightarrow \mathbb{R}$ be a Gâteaux differentiable and totally convex function. If $x_{0} \in E$ and the sequence $\left\{D_{f}\left(x_{n}, x_{0}\right)\right\}$ is bounded, then the sequence $\left\{x_{n}\right\}$ is bounded too.

Lemma 1.8 [22] Let $f: E \rightarrow \mathbb{R}$ be a Gâteaux differentiable and totally convex function, $x_{0} \in E$ and let $C$ be a nonempty, closed, and convex subset of $E$. Suppose that the sequence $\left\{x_{n}\right\}$ is bounded and any weak subsequential limit of $\left\{x_{n}\right\}$ belongs to C. If $D_{f}\left(x_{n}, x_{0}\right) \leq$ $D_{f}\left(P_{C}^{f}\left(x_{0}\right), x_{0}\right)$ for any $n \in \mathbb{R}$, then $\left\{x_{n}\right\}$ converges strongly to $P_{C}^{f}\left(x_{0}\right)$.

A mapping $T$ is said to be Bregman firmly nonexpansive [23], if for all $x, y \in C$,

$$
\langle\nabla f(T x)-\nabla f(T y), T x-T y\rangle \leq\langle\nabla f(x)-\nabla f(y), T x-T y\rangle
$$

or, equivalently,

$$
D_{f}(T x, T y)+D_{f}(T y, T x)+D_{f}(T x, x)+D_{f}(T y, y) \leq D_{f}(T x, y)+D_{f}(T y, x) .
$$


A point $p \in C$ is said to be asymptotic fixed point of a map $T$, if there exists a sequence $\left\{x_{n}\right\}$ in $C$ which converges weakly to $p$ such that $\lim _{n \rightarrow \infty}\left\|x_{n}-T x_{n}\right\|=0$. We denote by $\hat{F}(T)$ the set of asymptotic fixed points of $T$. A point $p \in C$ is said to be strong asymptotic fixed point of a map $T$, if there exists a sequence $\left\{x_{n}\right\}$ in $C$ which converges strongly to $p$ such that $\lim _{n \rightarrow \infty}\left\|x_{n}-T x_{n}\right\|=0$. We denote by $\tilde{F}(T)$ the set of strong asymptotic fixed points of $T$. Let $f: E \rightarrow \mathbb{R}$, a mapping $T: C \rightarrow C$ is said to be Bregman relatively nonexpansive [24] if $F(T) \neq \emptyset, \hat{F}(T)=F(T)$ and $D_{f}(p, T(x)) \leq D_{f}(p, x)$ for all $x \in C$ and $p \in F(T)$. The map $T: C \rightarrow C$ is said to be Bregman weak relatively nonexpansive if $F(T) \neq \emptyset, \tilde{F}(T)=F(T)$ and $D_{f}(p, T(x)) \leq D_{f}(p, x)$ for all $x \in C$ and $p \in F(T)$. $T$ is said to be quasi-Bregman relatively nonexpansive if $F(T) \neq \emptyset$, and $D_{f}(p, T(x)) \leq D_{f}(p, x)$ for all $x \in C$ and $p \in F(T)$. In [22] quasi-Bregman relatively nonexpansive is called left quasi-Bregman relatively nonexpansive. A map $T: C \rightarrow C$ is called right quasi-Bregman relatively nonexpansive [25] if $F(T) \neq \emptyset$, and $D_{f}(T(x), p) \leq D_{f}(x, p)$ for all $x \in C$ and $p \in F(T)$. $T$ is said to be quasiBregman strictly pseudocontractive if there exist a constant $k \in[0,1)$ and $F(T) \neq \emptyset$ such that $D_{f}(p, T x) \leq D_{f}(p, x)+k D_{f}(x, T x)$ for all $x \in C$ and $p \in F(T)$. In particular, $T$ is said to be quasi-Bregman relatively nonexpansive if $k=0$ and $T$ is said to be quasi-Bregman pseudocontractive if $k=1$.

Very recently, Zhou and Gao [9] introduced this definition of a quasi-strict pseudocontraction related to the function $\phi$ and proved the convergence of a hybrid projection algorithm to a fixed point of a closed and quasi-strict pseudocontraction in a smooth and uniformly convex Banach space. They studied the strong convergence of the following scheme:

$$
\left\{\begin{array}{l}
x_{0} \in E \\
C_{1}=C \\
x_{1}=\prod_{C_{1}}\left(x_{0}\right), \\
C_{n+1}=\left\{z \in C_{n}: \phi\left(x_{n}, T x_{n}\right) \leq \frac{2}{1-k}\left\langle x_{n}-z, J x_{n}-J T x_{n}\right\rangle\right\} \\
x_{n+1}=\prod_{C_{n+1}}\left(x_{0}\right),
\end{array}\right.
$$

where $\prod_{C_{n+1}}$ is the generalized projection from $E$ onto $C_{n+1}$. They proved that the sequence $\left\{x_{n}\right\}$ converges strongly to $\prod_{F(T)}\left(x_{0}\right)$.

Recently, Zegeye and Shahzad [26] proved a strong convergence theorem for the common fixed point of a finite family of right Bregman strongly nonexpansive mappings in a reflexive Banach space. Alghamdi et al. [27] proved a strong convergence theorem for the common fixed point of a finite family of quasi-Bregman nonexpansive mappings. Pang et al. [28] proved weak convergence theorems for Bregman relatively nonexpansive mappings. Shahzad and Zegeye [29] proved a strong convergence theorem for multivalued Bregman relatively nonexpansive mappings, while Zegeye and Shahzad [30] proved a strong convergence theorem for a finite family of Bregman weak relatively nonexpansive mappings.

Motivated and inspired by the above works, in this paper, we prove a new strong convergence theorem for a finite family of closed quasi-Bregman strictly pseudocontractive mapping and a system of equilibrium problems in a real reflexive Banach space. These results generalize and improve several recent results. We showed by an example that the class of quasi-Bregman strictly pseudocontractive mappings is a proper generalization of the class of quasi- $\phi$-Bregman strictly pseudocontractive mappings. 


\section{Preliminaries}

The next lemma will be useful in the proof of our main results.

Lemma 2.1 Letf $: E \rightarrow \mathbb{R}$ be a Legendre function which is uniformly Fréchet differentiable and bounded on subsets of $E$, let $C$ be a nonempty, closed, and convex subset of $E$ and let $T: C \rightarrow C$ be a quasi-Bregman strictly pseudocontractive mapping with respect to $f$. Then, for any $x \in C, p \in F(T)$ and $k \in[0,1)$ the following hold:

$$
D_{f}(x, T x) \leq \frac{1}{1-k}\langle\nabla f(x)-\nabla f(T x), x-p\rangle .
$$

Proof Let $x \in C, p \in F(T)$ and $k \in[0,1)$, by definition of $T$, we have

$$
D_{f}(p, T x) \leq D_{f}(p, x)+k D_{f}(x, T x)
$$

and, from (1.2), we obtain

$$
D_{f}(p, x)+D_{f}(x, T x)+\langle\nabla f(x)-\nabla f(T x), p-x\rangle \leq D_{f}(p, x)+k D_{f}(x, T x),
$$

which implies

$$
D_{f}(x, T x) \leq \frac{1}{1-k}\langle\nabla f(x)-\nabla f(T x), x-p\rangle .
$$

This completes the proof.

Lemma 2.2 [31] Let $E$ be a real reflexive Banach space, $f: E \rightarrow(-\infty,+\infty$ ] be a proper lower semi-continuous function, then $f^{*}: E^{*} \rightarrow(-\infty,+\infty]$ is a proper weak ${ }^{*}$ lower semicontinuous and convex function. Thus, for all $z \in E$, we have

$$
D_{f}\left(z, \nabla f^{*}\left(\sum_{i=1}^{N} t_{i} \nabla f\left(x_{i}\right)\right)\right) \leq \sum_{i=1}^{N} t_{i} D_{f}\left(z, x_{i}\right) .
$$

In order to solve the equilibrium problem, let us assume that a bifunction $g: C \times C \rightarrow \mathbb{R}$ satisfies the following conditions [1]:

(A1) $g(x, x)=0, \forall x \in C$;

(A2) $g$ is monotone, i.e., $g(x, y)+g(y, x) \leq 0, \forall x, y \in C$;

(A3) $\lim \sup _{t \downarrow 0} g(x+t(z-x), y) \leq g(x, y), \forall x, z, y \in C$;

(A4) the function $y \mapsto g(x, y)$ is convex and lower semi-continuous.

The resolvent of a bifunction $g$ [2] is the operator $\operatorname{Res}_{g}^{f}: E \rightarrow 2^{C}$ defined by

$$
\operatorname{Res}_{g}^{f}(x)=\{z \in C: g(z, y)+\langle\nabla f(z)-\nabla f(x), y-z\rangle \geq 0, \forall y \in C\} .
$$

From Lemma 1 , in [32], if $f:(-\infty,+\infty] \rightarrow \mathbb{R}$ is a strongly coercive and Gâteaux differentiable function, and $g$ satisfies conditions (A1)-(A4), then $\operatorname{dom}\left(\operatorname{Res}_{g}^{f}\right)=E$. The following lemma gives some characterization of the resolvent $\operatorname{Res}_{g}^{f}$.

Lemma 2.3 [32] Let E be a real reflexive Banach space and $C$ be a nonempty closed convex subset of $E$. Let $f: E \rightarrow(-\infty,+\infty]$ be a Legendre function. If the bifunction $g: C \times C \rightarrow \mathbb{R}$ satisfies the conditions (A1)-(A4), then the following hold: 
(i) $\operatorname{Res}_{g}^{f}$ is single-valued;

(ii) $\operatorname{Res}_{g}^{f}$ is a Bregman firmly nonexpansive operator;

(iii) $F\left(\operatorname{Res}_{g}^{f}\right)=\mathrm{EP}(g)$;

(iv) $\mathrm{EP}(g)$ is closed and convex subset of $C$;

(v) for all $x \in E$ and for all $q \in F\left(\operatorname{Res}_{g}^{f}\right)$, we have

$$
D_{f}\left(q, \operatorname{Res}_{g}^{f}(x)\right)+D_{f}\left(\operatorname{Res}_{g}^{f}(x), x\right) \leq D_{f}(q, x)
$$

\section{Main result}

Lemma 3.1 Letf $: E \rightarrow \mathbb{R}$ be a Legendre function which is uniformly Fréchet differentiable on bounded subsets of $E$, let $C$ be a nonempty, closed, and convex subset of $E$ and let $T: C \rightarrow$ $C$ be a quasi-Bregman strictly pseudocontractive mapping with respect to $f$. Then $F(T)$ is closed and convex.

Proof Let $F(T)$ be nonempty set. First we show that $F(T)$ is closed. Let $\left\{x_{n}\right\}$ be a sequence in $F(T)$ such that $x_{n} \rightarrow z$ as $n \rightarrow \infty$, we need to show that $z \in F(T)$. From Lemma 2.1, we obtain

$$
D_{f}(z, T z) \leq \frac{1}{1-k}\left\langle\nabla f(z)-\nabla f(T z), z-x_{n}\right\rangle .
$$

From (3.1), we have $D_{f}(z, T z) \leq 0$, and from [15], Lemma 7.3, it follows that $T z=z$. Therefore $F(T)$ is closed.

Next, we show that $F(T)$ is convex. Let $z_{1}, z_{2} \in F(T)$, for any $t \in(0,1)$; putting $z=t z_{1}+$ $(1-t) z_{2}$, we need to show that $z \in F(T)$. From Lemma 2.1, we obtain, respectively,

$$
D_{f}(z, T z) \leq \frac{1}{1-k}\left\langle\nabla f(z)-\nabla f(T z), z-z_{1}\right\rangle
$$

and

$$
D_{f}(z, T z) \leq \frac{1}{1-k}\left\langle\nabla f(z)-\nabla f(T z), z-z_{2}\right\rangle .
$$

Multiplying (3.2) by $t$ and (3.3) by $(1-t)$ and adding the results, we obtain

$$
D_{f}(z, T z) \leq \frac{1}{1-k}\langle\nabla f(z)-\nabla f(T z), z-z\rangle
$$

which implies $D_{f}(z, T z) \leq 0$, and from [15], Lemma 7.3, it follows that $T z=z$. Therefore $F(T)$ is also convex. This completes the proof.

We now prove the following theorem.

Theorem 3.2 Let $C$ be a nonempty, closed, and convex subset of a real reflexive Banach space $E$ and $f: E \rightarrow \mathbb{R}$ a strongly coercive Legendre function which is bounded, uniformly Fréchet differentiable and totally convex on bounded subset of $E$. For each $k=1,2, \ldots, m$, let $g_{k}$ be a bifunction from $C \times C$ to $\mathbb{R}$ satisfying (A1)-(A4) and let $\left\{T_{i=1}^{N}\right\}$ be a finite family of $L_{i}$-Lipschitzian, $i=1,2,3, \ldots, N$, closed and quasi-Bregman strictly pseudocontractive self 
mappings of $C$ such that $F:=\left(\bigcap_{k=1}^{m} \operatorname{EP}\left(g_{k}\right)\right) \cap\left(\bigcap_{i=1}^{N} F\left(T_{i}\right)\right) \neq \emptyset$. Let $\left\{x_{n}\right\}_{n=1}^{\infty}$ be a sequence generated by $x_{1}=x \in C, C_{1}=C$ and

$$
\left\{\begin{aligned}
& x_{1} \in C \\
& y_{n}=\nabla f^{*}\left(\alpha_{n} \nabla f\left(x_{n}\right)+\left(1-\alpha_{n}\right) \nabla f\left(T_{n} x_{n}\right)\right) \\
& u_{j, n}=\operatorname{Res}_{g_{j}}^{f} y_{n}, \quad j=1,2,3, \ldots, m \\
& w_{n}=\nabla f^{*}\left(\sum_{j=1}^{m} \beta_{j, n} \nabla f\left(u_{j, n}\right)\right) \\
& C_{n+1}=\left\{w \in C_{n}: D_{f}\left(x_{n}, w_{n}\right) \leq \frac{1}{1-k}\left\langle\nabla f\left(x_{n}\right)\right.\right. \\
&\left.\left.\quad-\nabla f\left(T_{n} x_{n}\right), x_{n}-w\right\rangle+\left\langle\nabla f\left(T_{n} x_{n}\right)-\nabla f\left(w_{n}\right), x_{n}-w\right\rangle\right\} \\
& x_{n+1}=P_{C_{n+1}}^{f}(x), \quad n \in \mathbb{N}
\end{aligned}\right.
$$

where $T_{n}=T_{n(\bmod N)}$, and $k \in[0,1)$, for each $i=1,2, \ldots, N, T_{i}$ is uniformly continuous; suppose $\left\{\alpha_{n}\right\}_{n=1}^{\infty}$ and $\left\{\beta_{j, n}\right\}_{n=1}^{\infty}, j=1,2, \ldots$, m are sequences in $(0,1)$ such that $(\mathrm{i}) \liminf _{n \rightarrow \infty}(1-$ $\left.\alpha_{n}\right)>0$, (ii) $\sum_{j=1}^{m} \beta_{j, n}=1, n \geq 1$. Then $\left\{x_{n}\right\}_{n=1}^{\infty}$ converges strongly to $P_{F}^{f}(x)$, where $P_{F}^{f}$ is the Bregman projection of $E$ onto $F$.

Proof The proof is divided into six steps.

Step I. Show that $F=\left(\bigcap_{j=1}^{m} \operatorname{EP}\left(g_{j}\right)\right) \cap\left(\bigcap_{i=1}^{N} F\left(T_{i}\right)\right)$ is closed and convex. From Lemma 3.1, $\bigcap_{i=1}^{N} F\left(T_{i}\right)$ is closed and convex and from (iv) of Lemma 2.3, $\bigcap_{j=1}^{m} \mathrm{EP}\left(g_{j}\right)$ is closed and convex. So, $F=\left(\bigcap_{j=1}^{m} \mathrm{EP}\left(g_{j}\right)\right) \cap\left(\bigcap_{i=1}^{N} F\left(T_{i}\right)\right)$ is closed and convex.

Step II. Show that $C_{n}$ is closed and convex for all $n \geq 1$. For $n=1, C_{1}=C$ is closed and convex. Assume that $C_{h}$ is closed and convex for some $h>1$. For $w \in C_{h+1}$, one obtains

$$
\begin{aligned}
D_{f}\left(x_{h}, w_{h}\right) \leq & \frac{1}{1-k}\left\langle\nabla f\left(x_{h}\right)-\nabla f\left(T_{h} x_{h}\right), x_{h}-w\right\rangle \\
& +\left\langle\nabla f\left(T_{h} x_{h}\right)-\nabla f\left(w_{h}\right), x_{h}-w\right\rangle ;
\end{aligned}
$$

using the fact that $\left\langle\nabla f\left(x_{h}\right)-\nabla f\left(T_{h} x_{h}\right), \cdot\right\rangle$ and $\left\langle\nabla f\left(T_{h} x_{h}\right)-\nabla f\left(w_{h}\right), \cdot\right\rangle$ are continuous and linear in $E$, for $h \geq 1, C_{h+1}$ is closed and convex.

Step III. Show that $F \subset C_{n}$ for every $n \geq 1$. Note that $F \subset C_{1}=C$. Suppose $F \subset C_{h}$, for $h \geq 1$, then for all $w \in F \subset C_{h}$, since $u_{j, h}=\operatorname{Res}_{g_{j}}^{f}\left(y_{h}\right)$ for each $j=1,2, \ldots, m$, from $(2.2)$ and Lemma 2.3, we have

$$
\begin{aligned}
D_{f}\left(w, w_{h}\right) & =D_{f}\left(w, \nabla f^{*}\left(\sum_{j=1}^{m} \beta_{j, n} \nabla f\left(u_{j, n}\right)\right)\right) \\
& \leq \sum_{j=1}^{m} \beta_{j h} D_{f}\left(w, u_{j h}\right) \\
& \leq \sum_{j=1}^{m} \beta_{j h} D_{f}\left(w, y_{h}\right) \\
& =D_{f}\left(w, y_{h}\right) ;
\end{aligned}
$$

also from (2.2) and (2.1), we obtain

$$
\begin{aligned}
D_{f}\left(w, y_{h}\right) & =D_{f}\left(w, \nabla f^{*}\left(\alpha_{h} \nabla f\left(x_{h}\right)+\left(1-\alpha_{h}\right) \nabla f\left(T_{h} x_{h}\right)\right)\right) \\
& \leq \alpha_{h} D_{f}\left(w, x_{h}\right)+\left(1-\alpha_{h}\right) D_{f}\left(w, T_{h} x_{h}\right)
\end{aligned}
$$




$$
\begin{aligned}
& \leq \alpha_{h} D_{f}\left(w, x_{h}\right)+\left(1-\alpha_{h}\right)\left[D_{f}\left(w, x_{h}\right)+k D_{f}\left(x_{h}, T_{h} x_{h}\right)\right] \\
& \leq D_{f}\left(w, x_{h}\right)+k D_{f}\left(x_{h}, T_{h} x_{h}\right) \\
& \leq D_{f}\left(w, x_{h}\right)+\frac{k}{1-k}\left\langle\nabla f\left(x_{h}\right)-\nabla f\left(T_{h} x_{h}\right), x_{h}-w\right\rangle .
\end{aligned}
$$

But, from (1.2),

$$
D_{f}\left(w, w_{h}\right)=D_{f}\left(w, x_{h}\right)+D_{f}\left(x_{h}, w_{h}\right)+\left\langle\nabla f\left(x_{h}\right)-\nabla f\left(w_{h}\right), w-x_{h}\right\rangle .
$$

From (3.6), (3.7), and (3.8), we obtain

$$
\begin{aligned}
D_{f}\left(x_{h}, w_{h}\right) \leq & \frac{k}{1-k}\left\langle\nabla f\left(x_{h}\right)-\nabla f\left(T_{h} x_{h}\right), x_{h}-w\right\rangle \\
& +\left\langle\nabla f\left(x_{h}\right)-\nabla f\left(w_{h}\right), x_{h}-w\right\rangle \\
= & \frac{k}{1-k}\left\langle\nabla f\left(x_{h}\right)-\nabla f\left(T_{h} x_{h}\right), x_{h}-w\right\rangle \\
& +\left\langle\nabla f\left(x_{h}\right)-\nabla f\left(T_{h} x_{h}\right), x_{h}-w\right\rangle \\
& +\left\langle\nabla f\left(T_{h} x_{h}\right)-\nabla f\left(w_{h}\right), x_{h}-w\right\rangle \\
= & \left.\frac{k}{1-k}+1\right)\left\langle\nabla f\left(x_{h}\right)-\nabla f\left(T_{h} x_{h}\right), x_{h}-w\right\rangle \\
& +\left\langle\nabla f\left(T_{h} x_{h}\right)-\nabla f\left(w_{h}\right), x_{h}-w\right\rangle \\
= & \frac{1}{1-k}\left\langle\nabla f\left(x_{h}\right)-\nabla f\left(T_{h} x_{h}\right), x_{h}-w\right\rangle \\
& +\left\langle\nabla f\left(T_{h} x_{h}\right)-\nabla f\left(w_{h}\right), x_{h}-w\right\rangle .
\end{aligned}
$$

This shows that $w \in C_{h+1}$, which implies $F \subset C_{n}$ for every $n \geq 1$.

Step IV. Show that $\lim _{n \rightarrow \infty} D_{f}\left(x_{n}, x\right)$ exists. From (3.5), $x_{n}=P_{C_{n}}^{f} x$, which from (a) of Lemma 1.4 implies

$$
\left\langle\nabla f(x)-\nabla f\left(x_{n}\right), y-x_{n}\right\rangle \leq 0, \quad \forall y \in C_{n} .
$$

Since $F \subset C_{n}$, we have

$$
\left\langle\nabla f(x)-\nabla f\left(x_{n}\right), w-x_{n}\right\rangle \leq 0, \quad \forall w \in F
$$

From (b) of Lemma 1.4 we have

$$
\begin{aligned}
D_{f}\left(x_{n}, x\right) & =D_{f}\left(P_{C_{n}}^{f} x, x\right) \leq D_{f}(w, x)-D_{f}\left(w, P_{C_{n}}^{f} x\right) \\
& \leq D_{f}(w, x), \quad \forall n \geq 1, w \in F .
\end{aligned}
$$

This implies that $\left\{D_{f}\left(x_{n}, x\right)\right\}$ is bounded, from Lemma 1.7, $\left\{x_{n}\right\}$ is bounded. By the construction of $C_{n}$, we have $x_{m} \in C_{m} \subset C_{n}$, and $x_{n}=P_{C_{n}}^{f} x$, for any positive integer $m \geq n$. Then we obtain

$$
\begin{aligned}
D_{f}\left(x_{m}, x_{n}\right) & =D_{f}\left(x_{m}, P_{C_{n}}^{f} x\right) \leq D_{f}\left(x_{m}, x\right)-D_{f}\left(P_{C_{n}}^{f} x, x\right) \\
& =D_{f}\left(x_{m}, x\right)-D_{f}\left(x_{n}, x\right) .
\end{aligned}
$$


In particular,

$$
D_{f}\left(x_{n+1}, x_{n}\right) \leq D_{f}\left(x_{n+1}, x\right)-D_{f}\left(x_{n}, x\right)
$$

Since $x_{n}=P_{C_{n}}^{f} x$ and $x_{n+1}=P_{C_{n+1}}^{f} x \in C_{n+1} \subset C_{n}$, we obtain $D_{f}\left(x_{n}, x\right) \leq D_{f}\left(x_{n+1}, x\right), \forall n \geq 1$.

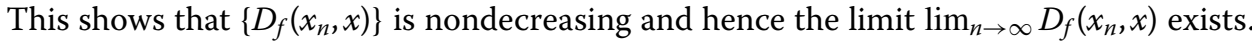
Thus from (3.12), taking the limit as $m, n \rightarrow \infty$, we obtain $\lim _{n \rightarrow \infty} D_{f}\left(x_{m}, x_{n}\right)=0$. Since $f$ is totally convex on bounded subsets of $E, f$ is sequentially consistent (see [17]). It follows that $\left\|x_{m}-x_{n}\right\| \rightarrow 0$ as $m, n \rightarrow \infty$. Hence $\left\{x_{n}\right\}$ is Cauchy sequence in $C$. As $\left\{x_{n}\right\}$ is Cauchy in a complete space $E$, there exists $p \in E$ such that $x_{n} \rightarrow p$ as $n \rightarrow \infty$. Clearly $p \in C$.

Since $D_{f}\left(x_{m}, x_{n}\right) \rightarrow 0$, as $m, n \rightarrow \infty$, we have in particular

$$
\lim _{n \rightarrow \infty} D_{f}\left(x_{n+1}, x_{n}\right)=0
$$

and this further implies that

$$
\lim _{n \rightarrow \infty}\left\|x_{n+1}-x_{n}\right\|=0 .
$$

Step V. Next we show that $x_{n} \rightarrow p \in F$.

Since $x_{n+1}=P_{C_{n+1}}^{f} x \in C_{n+1}$, we have from (3.5)

$$
\begin{aligned}
D_{f}\left(x_{n}, w_{n}\right) \leq & \frac{1}{1-k}\left\langle\nabla f\left(x_{n}\right)-\nabla f\left(T_{n} x_{n}\right), x_{n}-x_{n+1}\right\rangle \\
& +\left\langle\nabla f\left(T_{n} x_{n}\right)-\nabla f\left(w_{n}\right), x_{n}-x_{n+1}\right\rangle,
\end{aligned}
$$

which implies that $\lim _{n \rightarrow \infty} D_{f}\left(x_{n}, w_{n}\right)=0$. Since $f$ is totally convex on bounded subsets of $E, f$ is sequentially consistent (see [17]). It follows that

$$
\lim _{n \rightarrow \infty}\left\|x_{n}-w_{n}\right\|=0
$$

From (3.14) and (3.17), we have

$$
\lim _{n \rightarrow \infty}\left\|x_{n+1}-w_{n}\right\|=0 .
$$

Since $f$ is uniformly Fréchet differentiable, it follows from Lemma 1.1 that $\nabla f$ is uniformly continuous and $f$ is uniformly continuous on bounded subsets of $E$ (see [33], Theorem 1.8). Hence

$$
\lim _{n \rightarrow \infty}\left\|\nabla f\left(x_{n+1}\right)-\nabla f\left(w_{n}\right)\right\|=0
$$

and

$$
\lim _{n \rightarrow \infty}\left|f\left(x_{n+1}\right)-f\left(w_{n}\right)\right|=0 .
$$

Since $x_{n+1} \in C_{n+1}$, it follows from (3.6), (3.7) that

$$
\begin{aligned}
& f\left(x_{n+1}\right)-f\left(w_{n}\right)-\left\langle\nabla f\left(w_{n}\right), x_{n+1}-w_{n}\right\rangle \\
& \quad=D_{f}\left(x_{n+1}, w_{n}\right) \leq D_{f}\left(x_{n+1}, y_{n}\right) \leq D_{f}\left(x_{n+1}, x_{n}\right)+\frac{k}{1-k}\left\langle\nabla f\left(x_{n}\right)-\nabla f\left(T_{n} x_{n}\right), x_{n}-x_{n+1}\right\rangle,
\end{aligned}
$$


which implies from (3.20), (3.18), (3.13), and (3.14) that

$$
\lim _{n \rightarrow \infty} D_{f}\left(x_{n+1}, y_{n}\right)=0
$$

From the sequential consistency of $f$, we have

$$
\lim _{n \rightarrow \infty}\left\|x_{n+1}-y_{n}\right\|=0
$$

from (3.14) and (3.21), we obtain

$$
\lim _{n \rightarrow \infty}\left\|x_{n}-y_{n}\right\|=0
$$

which implies that $y_{n} \rightarrow p \in C$, since $x_{n} \rightarrow p \in C$. From the uniform continuity of $\nabla f$, we have

$$
\lim _{n \rightarrow \infty}\left\|\nabla f\left(x_{n}\right)-\nabla f\left(y_{n}\right)\right\|=0
$$

From (3.5), we have

$$
\left\|\nabla f\left(T_{n} x_{n}\right)-\nabla f\left(x_{n}\right)\right\|=\frac{1}{1-\alpha_{n}}\left\|\nabla f\left(x_{n}\right)-\nabla f\left(y_{n}\right)\right\|,
$$

which implies from (3.23) that

$$
\lim _{n \rightarrow \infty}\left\|\nabla f\left(T_{n} x_{n}\right)-\nabla f\left(x_{n}\right)\right\|=0
$$

Since $f$ is strongly coercive and uniformly convex on bounded subsets of $E, f^{*}$ is uniformly Fréchet differentiable on bounded sets. Moreover, $f^{*}$ is bounded on bounded sets, and from (3.24) we obtain

$$
\lim _{n \rightarrow \infty}\left\|T_{n} x_{n}-x_{n}\right\|=0
$$

On the other hand, we see that

$$
\begin{aligned}
\left\|x_{n}-T_{n+l} x_{n}\right\| \leq & \left\|x_{n}-x_{n+l}\right\|+\left\|x_{n+l}-T_{n+l} x_{n+l}\right\| \\
& +\left\|T_{n+l} x_{n+l}-T_{n+l} x_{n}\right\| \\
\leq & (1+L)\left\|x_{n}-x_{n+l}\right\|+\left\|x_{n+l}-T_{n+l} x_{n+l}\right\|
\end{aligned}
$$

for all $l \in\{1,2, \ldots, N\}$, where $L:=\sup _{1 \leq i \leq N} L_{i}$. It follows from (3.14) and (3.25) that

$$
\lim _{n \rightarrow \infty}\left\|x_{n}-T_{n+l} x_{n}\right\|=0
$$

for all $l \in\{1,2, \ldots, N\}$. Thus

$$
\lim _{n \rightarrow \infty}\left\|x_{n}-T_{l} x_{n}\right\|=0
$$


for all $l \in\{1,2, \ldots, N\}$. Since $x_{n} \rightarrow p$ as $n \rightarrow \infty$, by the closedness of $T_{l}$ for each $l \in$ $\{1,2, \ldots, N\}$, we obtain $p \in \bigcap_{l=1}^{N} F\left(T_{l}\right)$.

Also, since $y_{n} \rightarrow p$ as $n \rightarrow \infty$, we have from Lemma 2.3 , for each $j=1,2, \ldots, m$,

$$
0 \leq D_{f}\left(p, u_{j n}\right)=D_{f}\left(p, \operatorname{Res}_{g_{j}}^{f} y_{n}\right) \leq D_{f}\left(p, y_{n}\right) \rightarrow 0 \quad \text { as } n \rightarrow \infty .
$$

Then we have from Lemma 1.5 that $\lim _{n \rightarrow \infty}\left\|p-u_{j n}\right\|=0$, for each $j=1,2, \ldots, m$. Consequently, we have

$$
\left\|u_{j n}-y_{n}\right\| \leq\left\|u_{j n}-p\right\|+\left\|p-y_{n}\right\| \rightarrow 0 \quad \text { as } n \rightarrow \infty .
$$

From the uniform continuity of $\nabla f$, for each $j=1,2, \ldots, m$ we have

$$
\lim _{n \rightarrow \infty}\left\|\nabla f\left(u_{j n}\right)-\nabla f\left(y_{n}\right)\right\|=0 .
$$

From (2.3), we have, for $j=1,2, \ldots, m$,

$$
g_{j}\left(u_{j n}, y\right)+\left\langle\nabla f\left(u_{j n}\right)-\nabla f\left(y_{n}\right), y-u_{j n}\right\rangle \geq 0, \quad \forall y \in C .
$$

Furthermore, using (A2) in the last inequality, we obtain

$$
\left\langle\nabla f\left(u_{j n}\right)-\nabla f\left(y_{n}\right), y-u_{j n}\right\rangle \geq g_{j}\left(y, u_{j n}\right), \quad \forall y \in C .
$$

By (A4), (3.28), and $u_{j n} \rightarrow p$ as $n \rightarrow \infty$, we have

$$
g_{j}(y, p) \leq 0, \quad \forall y \in C
$$

Let $z_{t}:=t y+(1-t) p$ for $t \in(0,1]$ and $y \in C$. This implies that $z_{t} \in C$. This yields $g_{j}\left(z_{t}, p\right) \leq 0$. It follows from (A1) and (A4) that

$$
\begin{aligned}
0 & =g_{j}\left(z_{t}, z_{t}\right) \leq \operatorname{tg}_{j}\left(z_{t}, y\right)+(1-t) g_{j}\left(z_{t}, p\right) \\
& \leq \operatorname{tg}_{j}\left(z_{t}, y\right),
\end{aligned}
$$

and hence

$$
0 \leq g_{j}\left(z_{t}, y\right)
$$

From condition (A3), we obtain

$$
g_{j}(p, y) \geq 0, \quad \forall y \in C \text { and } \forall j \in\{1,2,3, \ldots, m\} .
$$

This implies that $p \in \operatorname{EP}\left(g_{j}\right)$, for each $j=1,2, \ldots, m$. Thus, $p \in \bigcap_{j=1}^{m} \operatorname{EP}\left(g_{j}\right)$. Hence we have $p \in F=\left(\bigcap_{i=1}^{N} F\left(T_{i}\right)\right) \cap\left(\bigcap_{j=1}^{m} \mathrm{EP}\left(g_{j}\right)\right)$.

Step VI. Finally, we show that $p=P_{F}^{f} x$. Setting $n \rightarrow \infty$ in (3.10), we obtain

$$
\langle\nabla f(x)-\nabla f(p), w-p\rangle \leq 0, \quad \forall w \in F
$$

By (a) of Lemma 1.4, we have $p=P_{F}^{f} x$. 
Here we give an example of a quasi-Bregman strictly peudocontractive mapping which is not quasi- $\phi$ strictly pseudocontractive mapping; this shows that the former class is a generalization of the latter.

Example 3.3 Let $E=\mathbb{R}, C=[-1,0]$ and define $T, f:[-1,0] \rightarrow \mathbb{R}$ by $f(x)=x$ and $T x=2 x$, for all $x \in[-1,0]$. We want to show that $T$ is a quasi-Bregman strictly pseudocontractive but not quasi- $\phi$ strictly pseudocontractive.

Proof From the definition it is clear that $f$ is proper, lower semi-continuous, and convex, and also $F(T)=\{0\}$. By the definition of quasi-Bregman strict pseudocontractivity, we find $k \in[0,1)$ such that $D_{f}(p, T x) \leq D_{f}(p, x)+k D_{f}(x, T x)$ for all $x \in C$ and $p \in F(T)$. Now,

$$
\begin{aligned}
D(0, T x) & =f(0)-f(T x)-\langle\nabla f(T x), 0-T x\rangle \\
& =0-2 x-\langle\nabla f(2 x), 0-2 x\rangle \\
& =-2 x-\langle 2,-2 x\rangle \\
& =-2 x+4 x=2 x, \\
D(0, x)= & f(0)-f(x)-\langle\nabla f(x), 0-x\rangle \\
& =0-x-\langle 1,-x\rangle \\
& =-x+x=0
\end{aligned}
$$

and

$$
\begin{aligned}
D(x, T x) & =f(x)-f(T x)-\langle\nabla f(T x), x-T x\rangle \\
& =x-2 x-\langle 2, x-2 x\rangle \\
& =-x+2 x=x .
\end{aligned}
$$

From (3.30), (3.31), and (3.32), we obtain

$$
\begin{aligned}
D(0, T x) & =2 x \leq x \\
& \leq 0+k x, \quad \forall x \in[-1,0], k \in[0,1) \\
& \leq D(0, x)+k D(x, T x), \quad \forall x \in[-1,0], k \in[0,1) .
\end{aligned}
$$

Therefore

$$
D(0, T x) \leq D(0, x)+k D(x, T x), \quad \forall x \in[-1,0], k \in[0,1) .
$$

Hence, $T$ is a quasi-Bregman strictly pseudocontractive map.

Further,

$$
\begin{aligned}
\phi(0, T x) & =|0|^{2}-2\langle 0, J(T x)\rangle+|T x|^{2} \\
& =0-2\langle 0, J(2 x)\rangle+|2 x|^{2} \\
& =4|x|^{2},
\end{aligned}
$$




$$
\begin{aligned}
\phi(0, x) & =|0|^{2}-2\langle 0, J(x)\rangle+|x|^{2} \\
& =0-2\langle 0, J(x)\rangle+|x|^{2} \\
& =|x|^{2}
\end{aligned}
$$

and

$$
\begin{aligned}
\phi(x, T x) & =|x|^{2}-2\langle x, J(T x)\rangle+|T x|^{2} \\
& =|x|^{2}-2\langle x, J(2 x)\rangle+4|x|^{2} \\
& =|x|^{2}-4|x, J(x)\rangle+4|x|^{2} \\
& =|x|^{2}-4|x|^{2}+4|x|^{2} \\
& =|x|^{2} .
\end{aligned}
$$

Since $4|x|^{2}>|x|^{2}+k|x|^{2}$, for all $k \in[0,1)$ and for all $x \in[-1,0]$,

$$
\phi(0, T x) \leq \phi(0, x)+k \phi(x, T x), \quad \forall x \in[-1,0]
$$

cannot hold for any $k \in[0,1)$. Hence, $T$ is not a quasi- $\phi$ strictly pseudocontractive map.

\section{Numerical example}

In this section we discuss the direct application of Theorem 3.2 on a typical example on a real line. Consider the following:

$$
\begin{aligned}
& \mathbb{E}=\mathbb{R}, \quad C=[-1,1], \quad g(z, y)=y^{2}+y z-2 z^{2}, \\
& f(x)=\frac{2}{3} x^{2}, \quad \nabla f(x)=\frac{4}{3} x, \quad T x=-2 x, \\
& f^{*}\left(x^{*}\right)=\sup \left\{\left\langle x^{*}, x\right\rangle-f(x): x \in \mathbb{E}\right\}, \\
& f^{*}(z)=\frac{3}{8} z^{2}, \quad \nabla f^{*}(z)=\frac{3}{4} z, \quad \alpha_{n}=\frac{n+1}{4 n}, \\
& \alpha_{n} \nabla f\left(x_{n}\right)+\left(1-\alpha_{n}\right) \nabla f\left(T x_{n}\right)=\frac{-(5 n-3)}{3 n} x_{n}, \\
& k=1 / 2, \quad x_{1}=1 / 2 \in C,
\end{aligned}
$$

then the scheme can be simplified as

$$
\begin{aligned}
& y_{n}=\nabla f^{*}\left(\alpha_{n} \nabla f\left(x_{n}\right)+\left(1-\alpha_{n}\right) \nabla f\left(T x_{n}\right)\right), \\
& \therefore y_{n}=\frac{-(5 n-3)}{4 n} x_{n}, \\
& u_{n}=\operatorname{Res}_{g}^{f} y_{n}=\frac{4}{13} y_{n}, \\
& w_{n}=\nabla f^{*}\left(\nabla f\left(u_{n}\right)\right)=u_{n}, \\
& C_{n+1}=\left\{w \in C_{n}: w \leq x_{n}-\frac{(1-k)\left(x_{n}-w_{n}\right)^{2}}{2\left[(1+2 k) x_{n}-(1-k) w_{n}\right]}\right\}, \\
& x_{n+1}=P_{C_{n+1}}^{f}\left(x_{1}\right)=x_{n}-\frac{(1-k)\left(x_{n}-w_{n}\right)^{2}}{2\left[(1+2 k) x_{n}-(1-k) w_{n}\right]} .
\end{aligned}
$$




\section{Competing interests}

The authors declare that they have no competing interests.

\section{Authors' contributions}

All authors contributed equally to the writing of this paper. All authors read and approved the final manuscript.

\section{Author details}

${ }^{1}$ Department of Mathematics, Michael Okpara University of Agriculture, Umudike, Abia State, Nigeria. ${ }^{2}$ Department of Mathematics, Ahmadu Bello University, Zaria, Nigeria. ${ }^{3}$ Department of Mathematical Sciences, Bayero University Kano, P.M.B. 3011, Kano, Nigeria.

\section{Received: 18 March 2014 Accepted: 16 October 2014 Published: 17 Nov 2014}

\section{References}

1. Blum, E, Oettli, W: From optimization and variational inequalities to equilibrium problems. Math. Stud. 63, 123-145 (1994)

2. Combettes, PL, Hirstoaga, SA: Equilibrium programming in Hilbert spaces. J. Nonlinear Convex Anal. 6, 117-136 (2005)

3. Tada, A, Takahashi, W: Strong convergence theorem for an equilibrium problem and a nonexpansive mapping. In: Tada, A, Takahashi, W (eds.) Nonlinear Analysis and Convex Analysis, pp. 609-617. Yokohama Publishers, Yokohama (2007)

4. Takahashi, W, Zembayashi, K: Strong and weak convergence theorems for equilibrium problems and relatively nonexpansive mappings in Banach spaces. Nonlinear Anal., Theory Methods Appl. 70(1), 45-57 (2009)

5. Takahashi, S, Takahashi, W: Viscosity approximation methods for equilibrium problems and fixed point problems in Hilbert spaces. J. Math. Anal. Appl. 1331(1), 372-379 (2003)

6. Nakajo, K, Takahashi, W: Strong convergence theorems for nonexpansive mappings and nonexpansive semigroups. J. Math. Anal. Appl. 279(2), 372-379 (2003)

7. Reich, S, Sabach, S: Three strong convergence theorems regarding iterative methods for solving equilibrium problems in reflexive Banach space. Contemp. Math. 568, 225-240 (2012)

8. Kassay, G, Reich, S, Sabach, S: Iterative methods for solving systems of variational inequalities in reflexive Banach space. SIAM J. Optim. 21, 1319-1344 (2011)

9. Zhou, H, Gao, E: An iterative method of fixed points for closed and quasi-strict pseudocontraction in Banach spaces. J. Appl. Math. Comput. 33, 227-237 (2010)

10. Hiriart-Urruty, JB, Lemarchal, C: Convex Analysis and Minimization Algorithms II. Grundlehren der Mathematischen Wissenschaften, vol. 306. Springer, Berlin (1993)

11. Zălinescu, C: Convex Analysis in General Vector Spaces. World Scientific, River Edge (2002)

12. Asplund, E, Rockafellar, RT: Gradients of convex functions. Trans. Am. Math. Soc. 139, 443-467 (1969)

13. Bonnans, JF, Shapiro, A: Perturbation Analysis of Optimization Problems. Springer, New York (2000)

14. Reich, S, Sabach, S: A strong convergence theorem for a proximal-type algorithm in reflexive Banach spaces. J. Nonlinear Convex Anal. 10, 471-485 (2009)

15. Bauschke, HH, Borwein, JM, Combettes, PL: Essential smoothness, essential strict convexity, and Legendre functions in Banach spaces. Commun. Contemp. Math. 3, 615-647 (2001)

16. Bauschke, $\mathrm{HH}$, Borwein, JM: Legendre functions and the method of random Bregman projections. J. Convex Anal. 4, 27-67 (1997)

17. Censor, Y, Lent, A: An iterative row-action method for interval convex programming. J. Optim. Theory Appl. 34 , 321-353 (1981)

18. Bregman, LM: The relaxation method for finding the common point of convex sets and its application to the solution of problems in convex programming. USSR Comput. Math. Math. Phys. 7, 200-217 (1967)

19. Butnariu, D, Resmerita, E: Bregman distances, totally convex functions and a method for solving operator equations in Banach spaces. Abstr. Appl. Anal. 2006, Article ID 84919 (2006)

20. Resmerita, E: On total convexity, Bregman projections and stability in Banach spaces. J. Convex Anal. 11, 1-16 (2004)

21. Butnariu, D, lusem, AN: Totally Convex Functions for Fixed Points Computation and Infinite Dimensional Optimization. Kluwer Academic, Dordrecht (2000)

22. Reich, S, Sabach, S: Two strong convergence theorems for a proximal method in reflexive Banach spaces. Numer. Funct. Anal. Optim. 31, 22-44 (2010)

23. Reich, S, Sabach, S: Existence and approximation of fixed points of Bregman firmly nonexpansive mappings in reflexive Banach spaces. In: Fixed-Point Algorithms for Inverse Problems in Science and Engineering, pp. 301-316. Springer, New York (2011)

24. Matsushita, S, Takahashi, W: Weak and strong convergence theorems for relatively nonexpansive mappings in Banach spaces. Fixed Point Theory Appl. 2004, 37-47 (2004)

25. Martin-Marquez, V, Reich, S, Sabach, S: Right Bregman nonexpansive operators in Banach spaces. Nonlinear Anal. 75, 5448-5465 (2012)

26. Zegeye, $\mathrm{H}$, Shahzad, N: Convergence theorems for right Bregman strongly nonexpansive mappings in reflexive Banach spaces. Abstr. Appl. Anal. 2014, Article ID 584395 (2014)

27. Alghamdi, MA, Shahzad, N, Zegeye, H: Strong convergence theorems for quasi-Bregman nonexpansive mappings in reflexive Banach spaces. J. Appl. Math. 2014, Article ID 580686 (2014)

28. Pang, CT, Naraghirad, E, Wen, CF: Weak convergence theorems for Bregman relatively nonexpansive mappings in Banach spaces. J. Appl. Math. 2014, Article ID 573075 (2014)

29. Shahzad, N, Zegeye, $\mathrm{H}$ : Convergence theorem for common fixed points of finite family of multivalued Bregman relatively nonexpansive mappings. Fixed Point Theory Appl. 2014, 152 (2014)

30. Zegeye, $\mathrm{H}$, Shahzad, N: Strong convergence theorems for common fixed point of finite family of Bregman weak relatively nonexpansive mappings in reflexive Banach spaces. Sci. World J. 2014, Article ID 493450 (2014)

31. Phelps, RP: Convex Functions, Monotone Operators, and Differentiability, 2nd edn. Lecture Notes in Mathematics, vol. 1364. Springer, Berlin (1993) 
32. Reich, S, Sabach, S: Two strong convergence theorems for Bregman strongly nonexpansive operators in reflexive Banach spaces. Nonlinear Anal. TMA 73, 122-135 (2010)

33. Ambrosetti, A, Prodi, G: A Primer of Nonlinear Analysis. Cambridge University Press, Cambridge (1993)

10.1186/1687-1812-2014-231

Cite this article as: Ugwunnadi et al.: Strong convergence theorem for quasi-Bregman strictly pseudocontractive mappings and equilibrium problems in Banach spaces. Fixed Point Theory and Applications 2014, 2014:231

Submit your manuscript to a SpringerOpen ${ }^{\odot}$ journal and benefit from:

- Convenient online submission

Rigorous peer review

- Immediate publication on acceptance

Open access: articles freely available online

- High visibility within the field

- Retaining the copyright to your article

Submit your next manuscript at $>$ springeropen.com 